
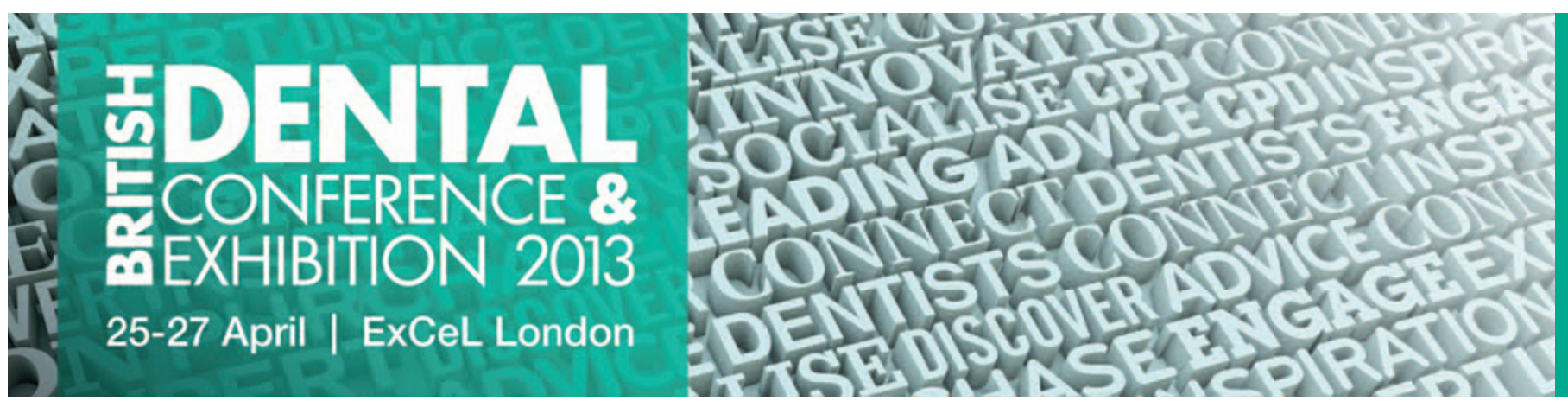

\title{
Avoiding medical emergencies
}

\author{
Y. Omar
}

\section{CORE VERIFIABLE CPD PAPER}

Medical emergencies can occur at any time in any location. This article and associated presentation at the forthcoming British Dental Conference \&t Exhibition provide key advice on avoiding medical emergencies in dental practice; including advice on risk assessing all patients, understanding the importance of a checklist, and using a National Early Warning Score (NEWS).

Much has been written about the common medical emergencies, particularly heart attack, syncope, epilepsy and cardiac arrest, but there seems to be less emphasis on the early detection and monitoring of the acutely ill patient. This paper will discuss three ways of avoiding medical emergencies in dental practice:

1. The American Society of

Anesthesiologists (ASA) physical

status classification system

2. The National Early Warning Score (NEWS)

3. The dental checklist.

Fabrice Muamba, the footballer, died on the pitch at Whitehart Lane on 17 March 2012. To his great fortune it was recognised early, CPR was started very quickly, defibrillation shocks were delivered within minutes and finally, he was accompanied to a specialist cardiac hospital by a cardiologist. He benefitted from an excellent 'chain of survival' (Fig. 1). An hour and a quarter later, and after 15 shocks, his heart had restarted and was stabilised. He is a lucky man to be alive and it is very unusual for one so young to experience a cardiac arrest without warning.

SSenior Teaching Fellow, Eastman Dental Institute, CPD, University College London

Correspondence to: Dr Yusof (Joe) Omar

Email:Yusof Omardryusofomar@aol.com

DOI: $10.1038 /$ sj.bdj.2013.217

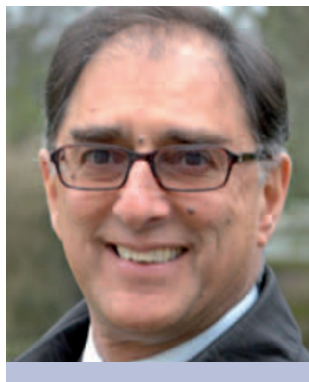

Joe Omar has been a lecturer in sedation at the Eastman Dental Institute, University College London since the inception of the Institute's sedation course. He spent his early years in South Africa before his family came to the UK. He qualified as a doctor from Cairo University in 1976 and returned to the UK to pursue a career in anaesthesia. He left the NHS in 1984 to establish a private practice in dental anaesthesia/sedation in the Harley Street area. Joe also lectures on medical emergencies for dental personnel, and has done so for over 25 years. Joe served on the 'Standing Committee for Sedation in Dentistry' at the RCS and RCoA from 2007 until 2010; during which time the guidelines on 'Alternative Techniques' were drawn up and published. He is currently President-elect of the Association of Dental Anaesthetists (ADA).

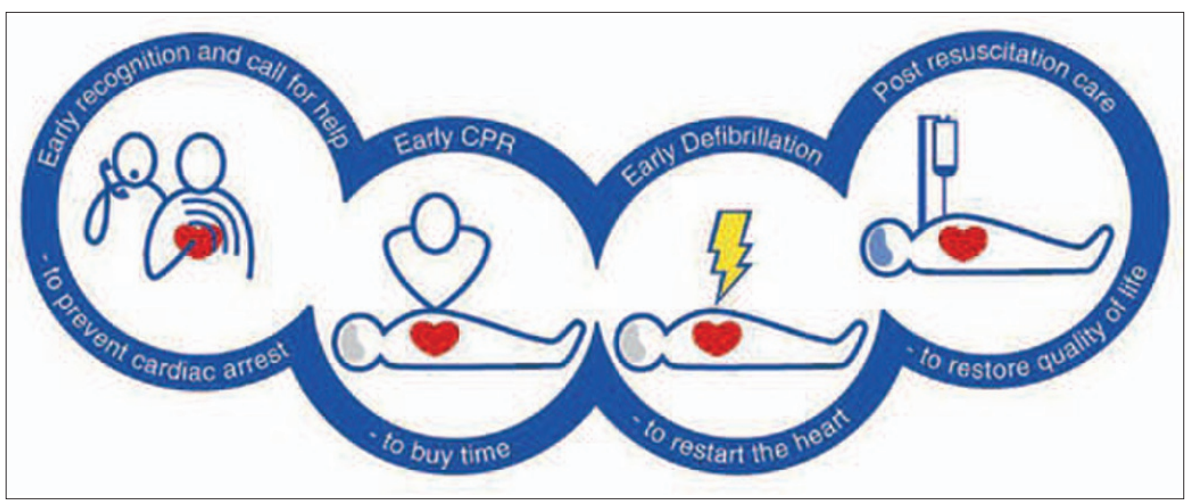

Fig. 1 The chain of survival. Image is reproduced with kind permission of Laerdal Medical. ${ }^{\circ} 2010$ Laerdal Medical (http://www.laerdal.com). All rights reserved.

\section{THE ASA PHYSICAL STATUS CLASSIFICATION SYSTEM}

Most deaths have an underlying cause and frequently there are warning signs which may or may not be recognised. It is for this reason that a good, updated, medical history is essential every time a patient undergoes treatment, and their ASA physical status is recorded according to the system indicated in Table 1. However, the ASA grading is of little use when a patient's condition is deteriorating dangerously in the surgery.

Death in dental practice is extremely rare and, fortunately, most dental teams will never have to deal with one. On the other hand, all dental teams are likely to see 'unwell' patients from time to time, 


\section{Table 1 American Society of}

Anesthesiologists (ASA) Physical status classification system

ASA physical status classification system

ASA 1 A normal healthy patient

ASA 2 A patient with mild systemic disease

ASA 3 A patient with severe systemic disease

ASA 4 A patient with severe systemic disease that is a constant threat to life

ASA 5 A moribund patient who is not expected to survive without the operation

and it is often difficult for the dental team to distinguish the 'wait and watch' case from the urgent or even critical illnesses.

Consider the hypothetical scenario; an elderly patient collapses, apparently lifeless, in the surgery, the receptionist witnesses it, shouts for help, and the dental team puts into action a well rehearsed plan. Preparing for a medical emergency such as this has become a core subject in continuing professional development (CPD) and has been drummed into every dental professional for the past two decades. It's what the Resuscitation Council (UK) has been advocating since it was founded in 1981 (resus.org.uk). ${ }^{1}$ Current teaching concentrates on:

- Risk-assessing the patient prior to treatment using the ASA classification

- Managing specific medical conditions such as chest pain and epilepsy

- Managing arrest with cardiopulmonary resuscitation (CPR).

'Currently, the dental team is not equipped to make an objective assessment of how ill their patient is.'

\section{THE NATIONAL EARLY WARNING SCORE (NEWS)}

The author of this paper has taught courses on medical emergencies and basic life support for 25 years and recurring questions from dental students and delegates are: 'Is it OK to send unwell patients home?' 'When should an ill patient be referred to their GP and when should an ambulance be called for?'

What if our hypothetical patient had not collapsed, but simply complained of feeling 'unwell'; then the options would be:

1. Continue the dental treatment as planned and hope the patient will improve

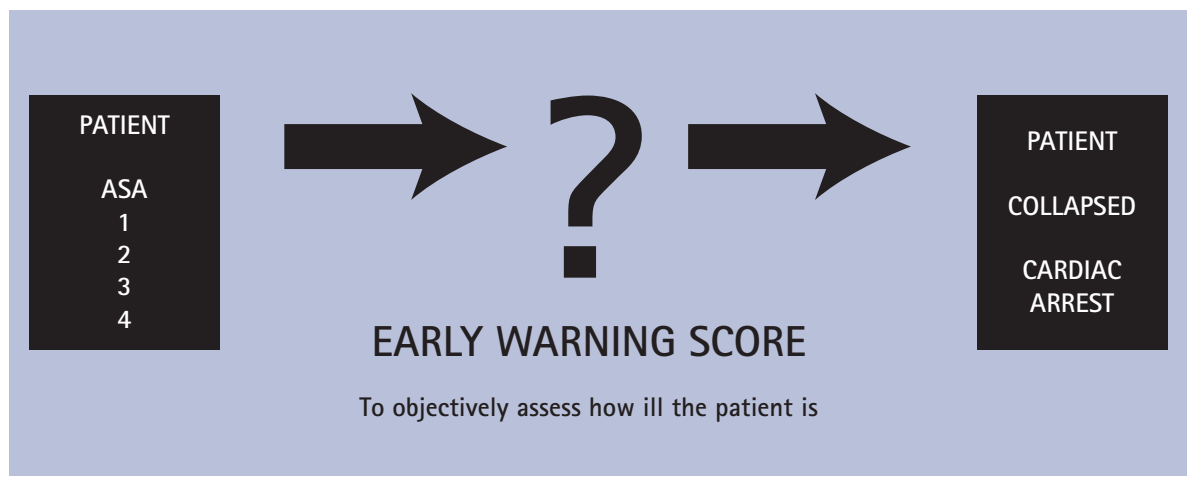

Fig.2 Early Warning Score

Observation chart for the National Early Warning Score (NEWS)

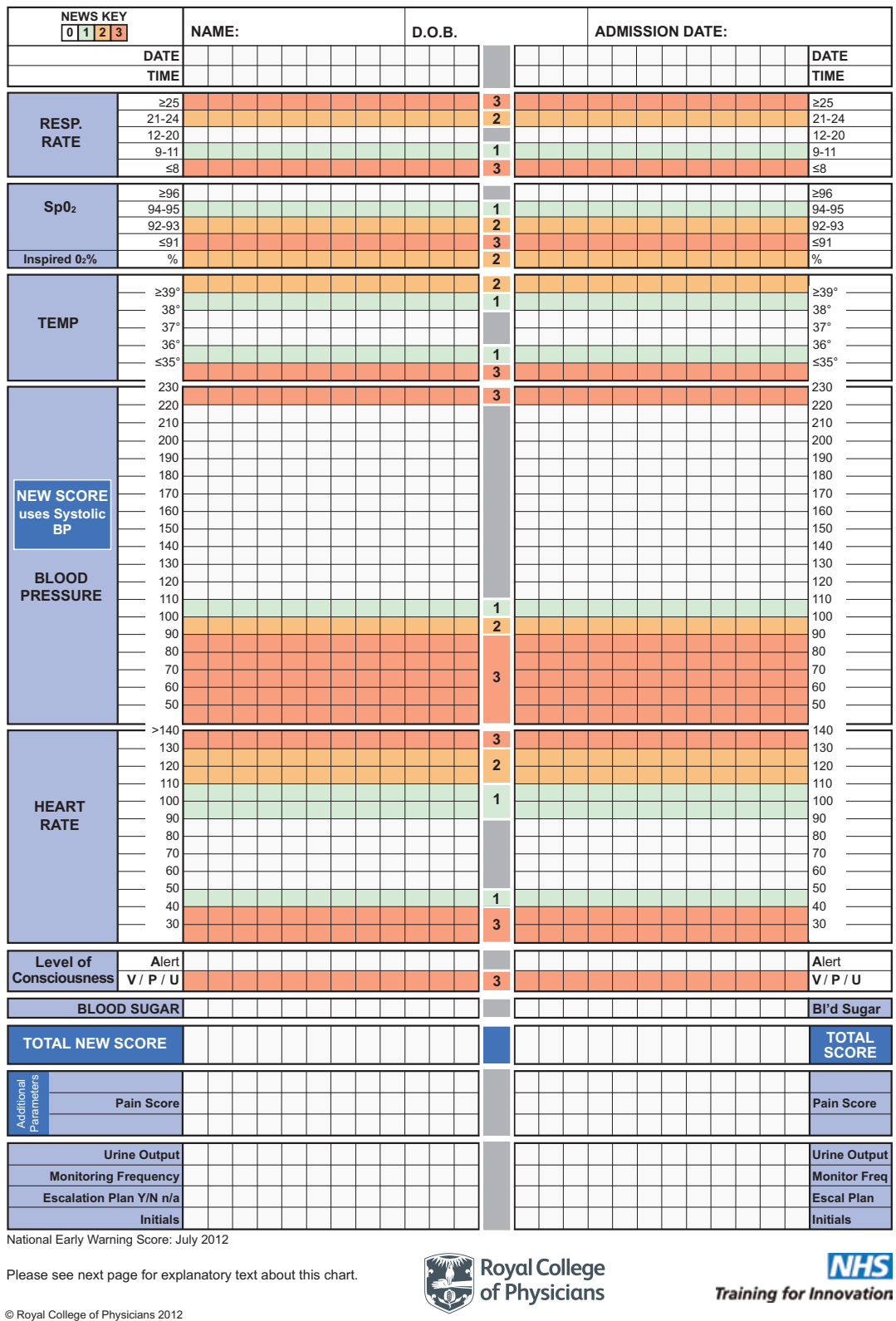

Fig. 3 Observation chart for the National Early Warning Score (NEWS). Image is reproduced with kind permission of the Royal College of Physicians.

2. Shorten the dental treatment and send the patient home

3. Abandon the treatment and send the patient home
4. Abandon the treatment and refer the patient to their GP

5. Refer the patient to the local A \& E department 


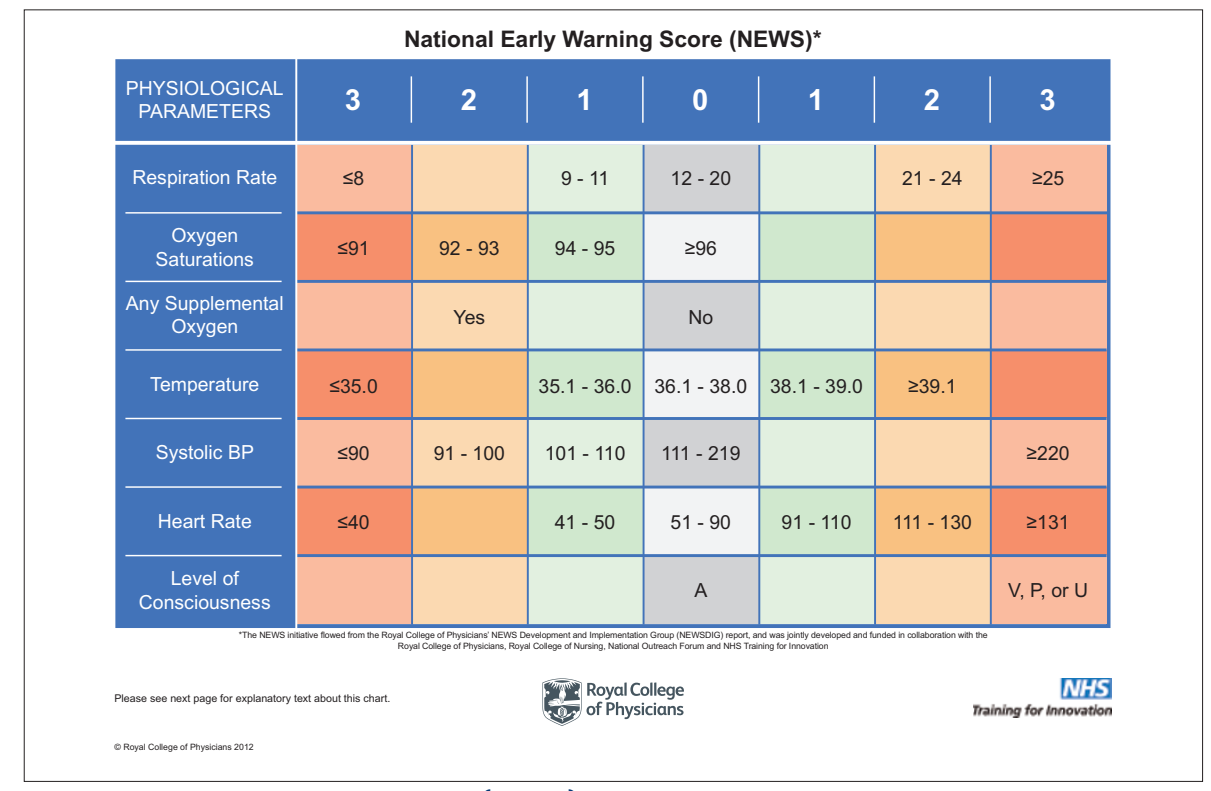

Fig. 4 National Early Warning Score (NEWS). Image is reproduced with kind permission of the Royal College of Physicians.

\section{Dial 999 for an ambulance, but on} what grounds?

Would the average dentist have sufficient training, knowledge and skill to assess which option to choose? It would seem dental teams are well rehearsed for the worst possible outcome, ie cardiac arrest, but not for assessing the degree of urgency with which to meet the patient's immediate needs. Triage is lacking; though, for it to be meaningful, even the most experienced clinician would need some basic physiological information. With this information almost anyone can decide whether to call for help and what kind of help to call for.

Distinguishing the acutely ill (or pre-arrest) patient has been a recurring problem in hospitals and various local attempts have been made to prevent the truly ill patient languishing on a busy ward unrecognised as such by busy staff. Many national reports, in the last decade, on acute clinical care advocated the use of early warning scores (EWS) to track changes and to trigger an escalation in care if needed (Fig. 2). However, these EWS systems were not standardised across the country and resulted in confusion when filling-in and reading the many diverse and eclectic charts.

Attempts were made to use the basic observations 'temperature, pulse, BP, respiratory rate, and oxygen saturation', which are also recorded by ambulance and paramedic personnel, in the pre-hospital environment, to help assess the degree of urgency with which to transfer the patient (Fig. 3).

In July 2012 the Royal College of Physicians published a report on a National Early Warning Score (NEWS). As the name implies the intention is to standardise the observations chart throughout the National Health Service.

The NEWS should also be used to standardise acute illness assessment in pre-hospital settings (Fig. 4). ' 'The NEWS is based on a simple scoring system in which a score is allocated to physiological measurements undertaken when a patient becomes or complains of feeling 'unwell.' Six simple physiological parameters form the basis of the scoring system:

1. Respiratory rate: This is very easily measured by looking at the patient's chest, counting the number of breaths taken against the clock, and recorded as 'breaths per minute'

2. Oxygen saturations: Oxygen saturation is measured with a pulse oximeter. Pulse oximetry is a non-invasive method allowing the monitoring of the saturation of a patient's hemoglobin. They range in size from thumb-size to large desktop models. They have become readily available and at very affordable prices (between £20 and £60). Simply turning it on, and attaching the probe to a finger, the oxygen saturation and pulse rate are displayed within seconds. The reading reflects how well the patient's blood is oxygenated by the lungs. The normal range of oxygen saturation is $95 \%$ or more

3. Temperature: Temperature is measured using a conventional under-the-tongue digital thermometer. Normal temperature is 37.2 degrees centigrade $\left(37^{\circ} \mathrm{C}\right)$

4. Systolic blood pressure: Blood pressure monitors (frequently referred to as non-invasive blood pressure, NIBP) are also readily available, cheap, and require little or no technical skill to use. Only the systolic reading is required for the NEWS

5. Pulse rate: Pulse can be read from the BP monitor or from the pulse oximeter, or may be taken manually at the radial or carotid pulse

6. Level of consciousness: this is measured according to the AVPU scale thus:

Awake: The patient is awake, conscious and able to talk but not necessarily orientated, and may be confused

Voice: the patient responds only to verbal stimuli

Pain: the patient only responds to pain stimuli

Unresponsive: the patient is unconscious and not responsive to verbal or pain stimuli.

In addition, a weighting score of two should be added for any patient requiring supplemental oxygen (oxygen delivery by mask or nasal cannulae). A score is allocated to each parameter as they are measured; the magnitude of the score reflecting how extreme the parameter varies from the norm. The score is then aggregated. The score is uplifted by two points for people requiring oxygen (Fig. 5). Table 2 gives the recommended action (by the author)* to take after measuring the six observations: ${ }^{3}$ temperature, pulse, $\mathrm{BP}$, respiratory rate, oxygen saturation and level of consciousness.

The NEWS applies only to adults aged 16 years and over. It should not be used for children and pregnant women.

\section{Benefits and cost of NEWS to the dentist}

Currently, the minimal list of equipment required for all dental practices, according to the Resuscitation Council 
(UK) document Medical Emergencies and Resuscitation in a Dental Environment, ${ }^{1}$ is as follows:

- Portable oxygen cylinder (D size) with pressure reduction valve and flowmeter

- Oxygen face mask with reservoir and tubing

- Basic set of oropharyngeal airways (sizes 1, 2, 3 and 4)

- Pocket mask with oxygen port

- Self-inflating bag and mask apparatus with oxygen reservoir and tubing (1 litre size bag) where staff have been appropriately trained

- Variety of well-fitting adult and child face masks for attaching to selfinflating bag

- Portable suction with appropriate suction catheters and tubing e.g., the Yankauer sucker

- Single use sterile syringes and needles

- 'Spacer' device for inhaled bronchodilators

- Automated blood glucose measurement device

- Automated external defibrillator.

The author estimates that the cost of the equipment above would be in the region of at least $£ 1,500$ to $£ 2,000$. The cost of additional equipment required for the purpose of NEWS would be under $£ 100$ to cover the purchase of the following:

- Finger pulse oximeter

- BP monitor

- Thermometer.

So, the added expense is not a huge burden in relation to the potential benefit to patients' wellbeing and peace of mind for practice team members.

In the event of a collapse with loss of consciousness, the correct approach remains the same: follow the $\mathrm{ABCDE}$ guidelines from the basic life support (BLS) algorithm. However, the value of the National Early Warning Score comes into play under two distinct scenarios:

1. Scoring ASA 2, 3 and 4 patients prior to treatment, particularly if the dental treatment is likely to be long, extensive, advanced, or 'emotionally taxing for the patient

2. Scoring any patient who feels or becomes unwell during or after dental treatment. Consecutive scores taken every ten minutes will reveal the

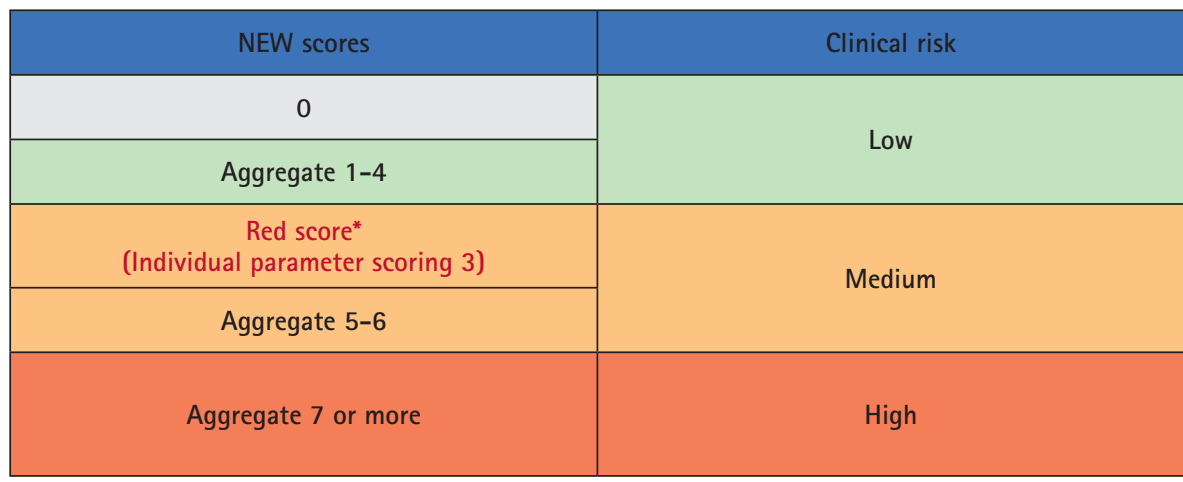

Fig. 5 NEWS thresholds and triggers. The NEWS trigger system aligned to the scale of clinical risk

Table 2 Recommended actions following NEWS assessment

\begin{tabular}{|l|l|l|}
\hline Score & Clinical risk & Dental management \\
\hline $1-4$ & Low & $\begin{array}{l}\text { A dentist must assess patient. Wait 5-10 minutes and re-assess/ } \\
\text { re-score. Consider shortening/postponing treatment. }\end{array}$ \\
\hline $\begin{array}{l}5-6 \\
\text { (or } 3 \text { in one parameter) }\end{array}$ & Medium & $\begin{array}{l}\text { Seek medical advice from GP or local AcEE or call NHS Direct } \\
\text { on 0845 4647. Continue monitoring every } 5 \text { min and look for } \\
\text { NEWS trend. }\end{array}$ \\
\hline 7 or more & High & $\begin{array}{l}\text { Abandon dental treatment. } \\
\text { Call 999 for ambulance immediately. }\end{array}$ \\
\hline
\end{tabular}

Table 3 The dental checklist

\begin{tabular}{|c|c|c|c|}
\hline $\begin{array}{l}\text { The day before and on } \\
\text { the appointment day }\end{array}$ & $\begin{array}{l}\text { Just prior to seeing } \\
\text { patient }\end{array}$ & $\begin{array}{l}\text { When you see the } \\
\text { patient }\end{array}$ & Just prior to discharge \\
\hline $\begin{array}{l}\text { Review today and } \\
\text { tomorrow's lists } \\
\text { Review: } \\
\text { Treatment plan } \\
\text { Medical history } \\
\text { ASA risk level } \\
\text { Need for antibiotics? }\end{array}$ & $\begin{array}{l}\text { Safe to use adrenaline? } \\
\text { Allergies? } \\
\text { List of plans: } \\
\text { Teeth to be done } \\
\text { Impressions } \\
\text { Jaw registrations }\end{array}$ & $\begin{array}{l}\text { Enquire about medical } \\
\text { history } \\
\text { ASA class } 3 \text { \& } 4 \\
\text { ? Assess NEWS } \\
\text { Final verbal consent } \\
\text { Do NOT forget: } \\
\text { Eye protection } \\
\text { Airway protection } \\
\text { Use rubber dam } \\
\text { Anxiety control }\end{array}$ & $\begin{array}{l}\text { Review list of plans } \\
\text { Removed all } \\
\text { foreign bodies: } \\
\text { Cotton rolls, pellets. } \\
\text { Packs } \\
\text { Retraction cords? } \\
\text { Special instructions } \\
\text { Specific information } \\
\text { Phone numbers } \\
\text { Dentist to patient } \\
\text { Patient to dentist }\end{array}$ \\
\hline
\end{tabular}

trend in their condition and help with on-going management.

Copies of the NEWS chart can be downloaded, free of charge, from the Royal College of Physicians web site and it is the author's view that at least two copies (in full colour) should be kept in the emergency kit and be used for every patient who becomes unwell whilst at the practice.

\section{THE DENTAL CHECKLIST}

The World Health Organisation (WHO) supports and recommends a checklist in all branches of surgery. 'Published on 10 November [2011] in the New England Journal of Medicine (NEJM), a study conducted in the Netherlands from October 2007 to March 2009 shows that with the use of a checklist, surgery complications were reduced by more than one-third and deaths reduced by almost half (from $1.5 \%$ to $0.8 \%$ ). ${ }^{3}$

Dentistry is a branch of surgery and has the potential for morbidity and mortality. The checklist is not intended to be comprehensive; additions and modifications to fit local practice are encouraged. ${ }^{4}$ Yet there are no checklists in regular use in the primary dental setting. Seventy percent of adverse events occur as a result of a lack of communication between team members. In view of this major cause of events 
the author would make the following recommendations:

1. Start the day with a staff meeting and discussion around 'today's list of patients' followed by 'tomorrow's list'. Briefing should centre around the following areas:

- Review treatment plan, medical history and ASA risk level. Are they mutually appropriate? For example, patients on warfarin should have extractions early in the day. Are there any factors to flag up; for example allergies, special instruments, special instructions etc? Is there enough time allocated for the treatment?

- The WHO trial showed that post op surgical infection can be reduced by $50 \%$ if antibiotic are given before incision, rather than following surgery.

2. Just before seeing a patient revise the medical history:

- Are there any contraindications to the use of adrenaline?

- Does the patient suffer from any allergies?

- Revise the treatment plan. List your plans.

3. When you see the patient:

- Ask if there are any changes to the medical history and, if there are, enquire further

- Ask if he/she understands the treatment being carried out and if he/she is happy to proceed.

4. Just prior to discharging the patient:

- Look at your list of plans and tick off tasks

- Have you removed cotton rolls and pledgets, retraction cords, etc

- Does the patient need any special instructions or information?

Checklists are used wherever there are potentials for human error and failure. Dentistry is not exempt from either of these, and it is the duty of every dental professional to protect patients from harm (Table 3).

Medical emergencies in dental practice will never be entirely eliminated, but much can be done to reduce their incidence;

- Insist on a medical history from every patient, and verbally go over the details. Beware the patient who gives a completely clear history, but has a poor memory

- Categorise every patient, on every visit, into an ASA class

- Design a checklist to suit your practice and get into the habit of using it

- If you are worried about a patient's health status or if you intend carrying out advanced dental treatment on ASA 3 \& 4 patients, start by recording their early warning score, and use it as a baseline. If they score 5 or 6 , seek advice from the patient's GP or hospital consultant.

Adherence to these actions on a daily basis will make for a safer environment for patients and a happier setting for the dental team.

1. Resuscitation Council (UK). General information about the Resuscitation Council, Background. Medical Emergencies and Resuscitation in a Dental Environment. London: Resuscitation Council (UK), 2004

2. Royal College of Physicians. NEWS. London: Royal College of Physicians. Available online at http:// www.rcplondon.ac.uk/resources/national-earlywarning-score-news (accessed February 2013).

3. New scientific evidence supports WHO findings: a surgical safety checklist could save hundreds of thousands of lives. Available online at http://www. who.int/patientsafety/safesurgery/checklist_saves_ lives/en/index.html (accessed February 2013).

4. World Health Organisation. WHO surgical safety checklist. Revised January 2009.

\section{FOOTNOTE:}

"Personal recommendation of the author, but open for discussion.

Joe Omar will speak on this topic on Saturday 27 April at the 2013 British Dental Conference \&t Exhibition at ExCeL, London. Register online: www.bda.org/conference. 